\title{
Modulation of radio frequency signals by ULF waves
}

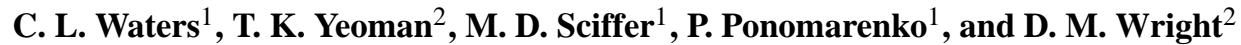 \\ ${ }^{1}$ School of Mathematical and Physical Sciences, The University of Newcastle, Callaghan, 2308, New South Wales, Australia \\ ${ }^{2}$ Department of Physics and Astronomy, University of Leicester, University Road, Leicester, LE1 7RH, UK
}

Received: 17 December 2006 - Revised: 22 April 2007 - Accepted: 7 May 2007 - Published: 4 June 2007

\begin{abstract}
The ionospheric plasma is continually perturbed by ultra-low frequency (ULF; $1-100 \mathrm{mHz}$ ) plasma waves that are incident from the magnetosphere. In this paper we present a combined experimental and modeling study of the variation in radio frequency of signals propagating in the ionosphere due to the interaction of ULF wave energy with the ionospheric plasma. Modeling the interaction shows that the magnitude of the ULF wave electric field, $\mathbf{e}$, and the geomagnetic field, $\mathbf{B}_{\mathbf{0}}$, giving an $\mathbf{e} \times \mathbf{B}_{\mathbf{0}} \mathrm{drift}$, is the dominant mechanism for changing the radio frequency. We also show how data from high frequency (HF) Doppler sounders can be combined with HF radar data to provide details of the spatial structure of ULF wave energy in the ionosphere. Due to spatial averaging effects, the spatial structure of ULF waves measured in the ionosphere may be quite different to that obtained using ground based magnetometer arrays. The ULF wave spatial structure is shown to be a critical parameter that determines how ULF wave effects alter the frequency of HF signals propagating through the ionosphere.
\end{abstract}

Keywords. Ionosphere (Ionosphere-magnetosphere interactions; Plasma waves and instabilities) - Magnetospheric physics (MHD waves and instabilities)

\section{Introduction}

The propagation of high frequency (HF; 3-30 MHz) signals via the ionosphere has been studied since the advent of radio. The ionospheric plasma causes refraction of the HF signal that facilitates long distance communication. While the telecommunications industry is relying more on higher frequency $(\mathrm{GHz})$ satellite transmissions, there remain applications for HF propagation, such as over-the-horizon radars (OTHR), that are sensitive to ionosphere dynamics. An im-

Correspondence to: C. L. Waters

(colin.waters@newcastle.edu.au) portant natural source of energy that perturbs the ionospheric plasma is ultra-low frequency (ULF; $1-100 \mathrm{mHz}$ ) plasma waves, incident from the near-Earth space environment. In this paper, we present two examples of HF signals that propagate in the ionosphere and change frequency in sympathy with incident ULF wave perturbations. The interaction between ULF wave activity and frequency changes in the HF signal are modeled using parameters tailored to the particular events. The detailed modeling shows the critical dependence of the interaction on the ULF wave spatial structure, which in turn is best determined using HF techniques.

The energy source for ULF waves in near-Earth space can be traced to solar activity. The magnetosphere, bow shock and magnetopause are ULF wave generation regions and these waves reach the mid and low latitude ionosphere after traversing the magnetosphere (Yumoto et al., 1985). ULF waves that can propagate through the cold plasma of the magnetosphere exist as two modes known as the fast and shear Alfvén, magnetohydrodynamic (MHD) wave modes (e.g. Stix, 1962). The presently accepted scenario is that fast mode waves that can propagate across the geomagnetic field, mode convert and excite the shear Alfvén mode (Dungey, 1954; Chen and Hasegawa, 1974; Southwood, 1974). An important property of the shear Alfvén mode is that the wave energy is guided along the geomagnetic field even if the propagation vector, $\mathbf{k}_{\mathbf{A}}$, is oblique to the geomagnetic field direction. For typical daytime ionosphere conditions, the shear Alfvén wave has a near unity reflection coefficient at conjugate ionospheres and forms field line resonances (FLRs) where the ULF amplitude is enhanced and the resonant frequency depends on latitude (Dungey, 1954; Samson and Rostoker, 1972; Takahashi, 1991; Waters, 2000). The ionosphere represents the inner boundary for near Earth space processes and in particular, ULF waves which are always present in the Earth's magnetosphere.

The propagation path, $s$, of HF signals in the ionosphere depends on the radio frequency, $f_{R}$, and the real part of the

Published by Copernicus GmbH on behalf of the European Geosciences Union. 
refractive index, $\mu$ as given by the Appleton-Hartree equation (e.g. Budden, 1985). Temporal variations in the refractive index produce a frequency shift, $\Delta f$, in the HF signal. For $\phi$, the angle between the direction of HF energy transport and the wave normal, the frequency shift is given by application of Fermat's principle as (e.g. Bennett, 1967)

$\Delta f=-\frac{f_{R}}{c} \int_{s} \frac{\partial \mu}{\partial t} \cos \phi d s$

where $c$ is the speed of light in vacuum. A mathematical description for the frequency shift in HF signals due to ULF energy in the ionosphere was formulated by Rishbeth and Garriott (1964) who proposed two mechanisms. The first involved a polarization electric field, generated in the $\mathrm{E}$ region and influencing the $\mathrm{F}$ region as an $\mathbf{e} \times \mathbf{B}_{\mathbf{0}}$ drift. The second mechanism described bulk motion of the $\mathrm{F}$ region plasma due to the ULF wave. Jacobs and Watanabe (1966) improved the model by including changes in the refractive index due to variations in the ionospheric electron distribution.

A more complete theory was developed in a series of papers by Poole and Sutcliffe (1987), Poole et al. (1988) and Sutcliffe and Poole $(1989,1990)$ which we will denote as the SP model. The variation in frequency was described as an effective Doppler "velocity", $V^{*}$, which is related to the frequency shift by (Poole et al., 1988),

$\Delta f=2 f_{R} \frac{V^{*}}{c}$

Assuming no overall gain or loss in the electron population, the SP model identified three mechanisms that might alter the ionosphere refractive index, thereby changing the HF frequency. For vertical incidence, $\mathbf{B}_{\mathbf{0}}$ has parallel or longitudinal, $\left(B_{L}\right)$ and transverse $\left(B_{T}\right)$ components to the radio wave normal direction. For $N$, the electron concentration and $z_{R}$, the HF reflection height, the Doppler velocity is given by (Poole et al., 1988)

$V^{*}=\int_{0}^{Z_{R}}\left[\frac{\partial \mu}{\partial B_{L}} \frac{\partial B_{L}}{\partial t}+\frac{\partial \mu}{\partial B_{T}} \frac{\partial B_{T}}{\partial t}+\frac{\partial \mu}{\partial N} \frac{\partial N}{\partial t}\right] d z$

For a coordinate system where $X$ is positive northward, $Y$ is positive eastward and $Z$ completes the right handed system, the Doppler velocity from the magnetic mechanism in the SP model is

$V_{1}=-i \omega \int_{0}^{Z_{R}}\left[\frac{\partial \mu}{\partial B_{L}} \frac{\partial B_{L}}{\partial t}+\frac{\partial \mu}{\partial B_{T}} \frac{\partial B_{T}}{\partial t}\right] d z$

where the background magnetic field, $\mathbf{B}_{\mathbf{0}}=\mathbf{B}_{\mathbf{L}}+\mathbf{B}_{\mathbf{T}}$, the vector sum of longitudinal and transverse components respectively and the magnetic field varies as $\mathbf{B}=\mathbf{B}_{\mathbf{0}}+\mathbf{b}_{\mathbf{0}} e^{-i \omega t}$. Equation (4) describes the change in $\mu$ due to magnetic field variations from the ULF wave. The advection mechanism involves the electron density, $N$, and is given by

$V_{2}=-\int_{0}^{Z_{R}}\left[\frac{\partial \mu}{\partial N}(v \cdot \nabla N)\right] d z$
This describes the vertical bulk motion of electrons driven by the electric field of the ULF wave and is essentially the same as the first mechanism described by Rishbeth and Garriott (1964). The compression mechanism is

$V_{3}=-\int_{0}^{Z_{R}}\left[\frac{\partial \mu}{\partial N} N(\nabla \cdot v)\right] d z$

which changes the refractive index by altering the electron density due to the compression/rarefraction of the plasma by the ULF wave fields.

Comparisons between ULF wave activity recorded by ground based magnetometers and associated variations in the frequency of HF waves reflected from the ionosphere have been reported by a number of researchers (Watermann, 1987; Menk, 1992; Wright et al., 1999). Most studies employ a "Doppler sounder" configuration consisting of a continuous wave (CW) transmitter/receiver system that monitors an ultra-stable frequency in the HF band. Phase-locked loop circuits in the receiver detect changes in frequency as a function of time while a nearby vector magnetometer monitors ULF wave activity.

ULF wave signatures have also been detected in the ionosphere using coherent-scatter radars. The ULF activity usually appears as FLRs, detected in the E-region (e.g. Walker et al., 1979; Yeoman et al., 1990) and F-region (e.g. Ruohoniemi et al., 1991; Fenrich et al., 1995) of the ionosphere. However, some non-resonant ULF wave signatures have also been reported (e.g. Allan et al., 1983). An important ULF wave parameter is the azimuthal wave number, $m$, which has been used to estimate the longitudinal spatial variation from ground based magnetometer array data for many years (e.g. Herron, 1966; Olson and Rostoker, 1978). For two magnetometers located at the same latitude, $\lambda$, separated by a distance in longitude of $S \mathrm{~km}$, the $m$ number was given by Olson and Rostoker (1978) as

$m=\frac{2 \pi R \Delta \phi}{360 S} \cos \lambda$

where $\mathrm{R}$ is the Earth radius $(\mathrm{km})$ and $\Delta \phi$ is the estimated phase difference in degrees. This is an important parameter in ULF wave research as ULF wave generation mechanisms based on the Kelvin-Helmholtz instability (e.g. Southwood, 1968) predict a specific range of values for $m$. Furthermore, the amplitude of ULF waves detected at the ground is reduced for large azimuthal wave numbers (Nishida, 1964; Hughes and Southwood, 1976a) effectively shielding high$m$ ULF wave activity from the ground. ULF wave spatial structures estimated from HF radar data have been compared with $m$ numbers obtained using ground based magnetometer array data. These comparisons have shown up to 5 times difference in values for $m$ (e.g. Ziesolleck et al., 1998). Ponomarenko et al. (2001) interpreted this discrepancy in terms of the spatial scale size of the ULF energy in the ionosphere and how a ground magnetometer integrates the contribution from the associated ionospheric currents. This has important 
implications for the SP models when comparing theory and experimental HF and ULF wave data in the ionosphere and on the ground.

Experimental studies comparing coherent scatter radar, Doppler sounder and ground magnetometer data have indicated that vertical bulk electron plasma motion driven by the electric field of the ULF wave is responsible for changes in the radio frequency (Wright et al., 1997; Yeoman et al., 2000). Parallel to these observations, the SP model has developed as the favoured theoretical description of these effects. However, model and experimental comparisons have only been reported in a general sense where the model comparisons are made using published figures and tables. Furthermore, the ULF wave electric field has previously been obtained from the model discussed by Hughes (1974) and Hughes and Southwood (1976b). Recent developments have improved this description, allowing for a mixture of incident fast and shear Alfvén modes and the inductive response of the ionosphere (Sciffer and Waters, 2002; Sciffer et al., 2004). In this paper, we take the coherent scatter radar, Doppler sounder and ground magnetometer data and run the SP and improved ULF wave models specifically for the observed experimental parameters. In order to do this, models for both ULF and HF wave propagation through the ionosphere are required. The SP model was coded directly from Sutcliffe and Poole (1989) using the electron collision frequencies and mobilities to estimate the $\mathbf{e} \times \mathbf{B}_{0}$ term. The model for the interaction of ULF waves with the ionosphere is more involved and is described in the next section.

\section{ULF waves and the ionosphere}

Ground based magnetometer arrays provide the main data source for studying ULF wave properties. Since the ULF wave energy must pass through the ionosphere to reach ground based sensors, a number of studies have examined the propagation of ULF waves from the magnetosphere through the ionosphere to the ground (Hughes, 1974; Ellis and Southwood., 1983; Waters et al., 2001; Ponomarenko et al., 2001; Sciffer et al., 2005). Analytic models treat the ionosphere as a thin current sheet whose properties can be characterised by height integrated Pedersen and Hall conductivities (Hughes, 1974; Sciffer and Waters, 2002). However, determining frequency shifts in HF signals due to ULF wave energy in the ionosphere requires a knowledge of the ULF wave fields as a function of altitude. One way of obtaining the altitude variation of ULF wave electric and magnetic fields is to use the procedure in Hughes (1974) and Hughes and Southwood (1976a). Their model was formulated as an initial value problem, which is susceptible to numerical swamping (Pitteway, 1965), and limited in application to incident shear Alfven mode waves. A more flexible formulation was given by Zhang and Cole $(1994,1995)$ who recast the equations as a boundary value problem. However, the Zhang and Cole formulation was developed for vertical $\mathbf{B}_{\mathbf{0}}$.

A boundary value formulation that allows for oblique $\mathbf{B}_{\mathbf{0}}$ and both MHD wave modes was developed by (Sciffer et al., 2005). ULF wave energy, incident from the magnetosphere is described as an electromagnetic disturbance. The relevant Maxwell equations are

$\nabla \times \mathbf{E}=-\frac{\partial \mathbf{B}}{\partial t}$
$\nabla \times \mathbf{H}=\mathbf{J}+\frac{\partial \mathbf{D}}{\partial \mathbf{t}}$

for the current density, $\mathbf{J}$ and magnetic flux density, $\mathbf{B}$ given by

$$
\begin{aligned}
\mathbf{J} & =\bar{\sigma} \mathbf{E} \\
\mathbf{B} & =\mu \mathbf{H}
\end{aligned}
$$

The Cartesian coordinate system of Sciffer and Waters (2002) is used where $X$ is northward, $Y$ is westward and $Z$ is radially outward from the surface of the Earth. The geomagnetic field, $\mathbf{B}_{\mathbf{0}}$, lies in the $X Z$ plane at an angle, $I$ to the horizontal. For no background electric field, $\left(\mathbf{E}_{\mathbf{0}}=\mathbf{0}\right)$,

$$
\begin{aligned}
& \mathbf{B}=\mathbf{B}_{\mathbf{0}}+\mathbf{b}=\left(\mathbf{B}_{\mathbf{0}} \cos (\mathbf{I}), \mathbf{0}, \mathbf{B}_{\mathbf{0}} \sin (\mathbf{I})\right)+\left(\mathbf{b}_{\mathbf{x}}, \mathbf{b}_{\mathbf{y}}, \mathbf{b}_{\mathbf{z}}\right) \\
& \mathbf{E}=\mathbf{E}_{\mathbf{0}}+\mathbf{e}=\left(\mathbf{e}_{\mathbf{x}}, \mathbf{e}_{\mathbf{y}}, \mathbf{e}_{\mathbf{z}}\right)
\end{aligned}
$$

Assuming the ionosphere medium varies only in the vertical direction and the horizontal spatial and time dependence is of the form $e^{i\left(k_{x} x+k_{y} y-\omega t\right)}$, the governing equations in component form are

$$
\begin{aligned}
0= & \frac{i k_{y} \epsilon_{13}}{\epsilon_{33}} b_{x}-\left(\frac{\partial}{\partial z}+\frac{i k_{x} \epsilon_{13}}{\epsilon_{33}}\right) b_{y} \\
& -i\left[\frac{k_{y}^{2}}{\omega}-\frac{\omega}{c^{2}}\left(\epsilon_{11}-\frac{\epsilon_{31} \epsilon_{13}}{\epsilon_{33}}\right)\right] e_{x} \\
& +i\left[\frac{k_{x} k_{y}}{\omega}+\frac{\omega}{c^{2}}\left(\epsilon_{12}-\frac{\epsilon_{32} \epsilon_{13}}{\epsilon_{33}}\right)\right] e_{y} \\
0= & \left(\frac{\partial}{\partial z}+\frac{i k_{y} \epsilon_{23}}{\epsilon_{33}}\right) b_{x}+\frac{i k_{x} \epsilon_{23}}{\epsilon_{33}} b_{y} \\
& -i\left[\frac{k_{x} k_{y}}{\omega}+\frac{\omega}{c^{2}}\left(\epsilon_{21}-\frac{\epsilon_{31} \epsilon_{23}}{\epsilon_{33}}\right)\right] e_{x} \\
& -i\left[\frac{k_{y}^{2}}{\omega}-\frac{\omega}{c^{2}}\left(\epsilon_{22}-\frac{\epsilon_{32} \epsilon_{23}}{\epsilon_{33}}\right)\right] e_{y} \\
0= & \left(i \omega-\frac{c^{2} k_{y}^{2}}{\omega \epsilon_{33}}\right) b_{x}+\left(\frac{i c^{2} k_{x} k_{y}}{\omega \epsilon_{33}}\right) b_{y}+\frac{i k_{y} \epsilon_{31}}{\epsilon_{33}} e_{x} \\
& -\left(\frac{\partial}{\partial z}+\frac{i k_{y} \epsilon_{32}}{\epsilon_{33}}\right) e_{y} \\
0= & \frac{i c^{2} k_{x} k_{y}}{\omega \epsilon_{33}} b_{x}+\left(i \omega-\frac{c^{2} k_{x}^{2}}{\omega \epsilon_{33}}\right) b_{y} \\
& -\left(\frac{\partial}{\partial z}+\frac{i k_{x} \epsilon_{31}}{\epsilon_{33}}\right) e_{x}+\left(\frac{i k_{x} \epsilon_{32}}{\epsilon_{33}}\right) e_{y}
\end{aligned}
$$


The $\epsilon_{i j}$ are elements of the dielectric tensor, $\bar{\epsilon}$, which is related to the conductivity tensor, $\bar{\sigma}$, by (Zhang and Cole, 1994)

$\bar{\epsilon}=\bar{I}-\frac{i}{\epsilon_{0} \omega} \bar{\sigma}$

The form of the conductivity tensor for oblique $\mathbf{B}_{\mathbf{0}}$ was given by Sciffer and Waters (2002). For the present work, the elements of the conductivity tensor are functions of altitude. Equations (14) to (17) represent a system of four, first order differential equations involving spatial derivatives in height, $z$. To complete the set, the $e_{z}$ and $b_{z}$ ULF wave components are

$e_{z}=\frac{-k_{y} c^{2}}{\omega \epsilon_{33}} b_{x}+\frac{k_{x} c^{2}}{\omega \epsilon_{33}} b_{y}-\frac{\epsilon_{31}}{\epsilon_{33}} e_{x}-\frac{\epsilon_{32}}{\epsilon_{33}} e_{y}$

$b_{z}=\frac{k_{y}}{\omega} e_{x}-\frac{k_{x}}{\omega} e_{y}$

and we require four boundary conditions to solve the system.

Two of the boundary conditions are specified at the ground. We assume the Earth is a uniform, homogenous conductor of finite conductivity. Due to the small frequency, the ULF waves decay in amplitude in this medium and are described by

$$
\begin{aligned}
& \frac{\partial e_{x}}{\partial z}-\gamma\left(\sigma_{g}, k_{x}, k_{y}, \omega\right) e_{x}=0 \\
& \frac{\partial e_{y}}{\partial z}-\gamma\left(\sigma_{g}, k_{x}, k_{y}, \omega\right) e_{y}=0
\end{aligned}
$$

where $\gamma$ specifies the ground to be a uniform medium with conductivity, $\sigma_{g}=10^{-2} \mathrm{Mho} / \mathrm{m}$.

The top boundary was set at $1000 \mathrm{~km}$ where resistive MHD plasma conditions were assumed. The model was developed to allow for the existence of both the shear Alfvén and fast mode waves up to the top boundary. Details of the derivation for this type of boundary condition are given in Sciffer et al. $(2004,2005)$.

Equations (14) to (17) were solved using a second order finite differencing scheme and the Numerical Algorithms Group (NAG) package FO4ADF. The composition of the atmosphere was calculated from the thermosphere model based on satellite mass spectrometer and ground-based incoherent scatter data (MSISE90), (Hedin, 1991). The ionosphere composition was obtained using the International Reference Ionosphere (IRI2001) model and $\mathbf{B}_{\mathbf{0}}$ was obtained from the International Geomagnetic Reference Field (IGRF2000). Data for the respective collision frequencies below $80 \mathrm{~km}$ altitude were extrapolated to the ground using the expressions given in Zhang and Cole (1994).

\section{DOPE and ground magnetometer data}

The Doppler Pulsation Experiment (DOPE) is operated by the Radio and Space Plasma Physics Group at the University of Leicester, UK and has been recording coincident HF and ULF data since mid-1995. The DOPE system is located near Troms $\varnothing$, Norway (geographic: 69.6 N, 19.2 E) and consists of frequency stable transmitter/receivers (Yeoman et al., 2000). The system incorporates two altitude separated paths at 4.16 and $5.25 \mathrm{MHz}$ (Ramfjordmoen-Seljelvnes) that are used to check phase consistency to eliminate possible infrasonic modes, and two paths that are azimuthally separated from these at 5.73 and $5.26 \mathrm{MHz}$ (Ramfjordmoen-Skibotn and Ramfjordmoen-Kilpisjärvi, respectively). In this paper, we present data from the $4.16 \mathrm{MHz}$ path and azimuthal wave numbers from DOPE are calculated from the 5.25 and $5.73 \mathrm{MHz}$ path. Further details of the configuration are described in Yeoman et al. (2000). The transmitter radiates a fixed frequency, continuous wave $(\mathrm{CW})$ signal which is received $\sim 50 \mathrm{~km}$ away. Data at the receiver are sampled at $40 \mathrm{~Hz}$ and processed through a Fast Fourier Transform (FFT) algorithm (512 points per FFT) to provide a Doppler trace that has a time resolution of $12.8 \mathrm{~s}$. The ULF variations in the magnetic field were detected by the IMAGE vector magnetometer array (Luhr, 1994). The magnetometer data were sampled at $10 \mathrm{~s}$ intervals and are presented in geographic coordinates.

\subsection{Event 1: 25 March 2002}

Time series data, recorded 16:00-18:00 UT on 25 March 2002 by DOPE, the Super Dual Auroral Radar Network (SuperDARN) located near Hankasalmi (Finland) and the magnetometer located near Troms $\varnothing$ are shown in Fig. 1. The SuperDARN data, including received power and spectral width information (not shown) indicate that Doppler velocity variations seen over 16:40-17:20 UT by the Hankasalmi radar are from single hop, ground scatter. The DOPE data are derived from the FFT of the HF receiver data and the scatter of points (in $\mathrm{Hz}$ ) for each time slice indicates the spectral width. The DOPE time series shows a low frequency oscillation over 16:40-17:20 UT followed by a change to a higher frequency oscillation that does not appear in the magnetometer time series. For the oscillation after 17:20 UT, measurements from the multiple propagation paths from DOPE give an estimate of the longitudinal spatial structure as $m \sim 150$. A fast mode with this spatial scale would be highly evanescent. Therefore, this higher frequency, high-m oscillation is not a conventional fast mode driven FLR event. Since spatial integration effects prohibit this signal being detected by the ground magnetometer, we focus on the lower frequency, low-m event before 17:20 UT.

Coincident, ULF oscillations are seen in the radar, DOPE and magnetometer data over 16:40-17:20 UT. The Doppler shift is $0.4 \mathrm{~Hz}$ in "amplitude" around 17:00 UT. The magnetometer data is $6 \mathrm{nT}$ amplitude for the $\mathrm{X}$ (north-south) sensor with the $\mathrm{Y}$ (east-west) data smaller at $4 \mathrm{nT}$. The power spectrum of the magnetometer time series recorded at Troms $\varnothing$ (TRO) and the DOPE data are shown in Fig. 2. A prominent peak in power at $2.8 \mathrm{mHz}$ is evident. The spectrum 


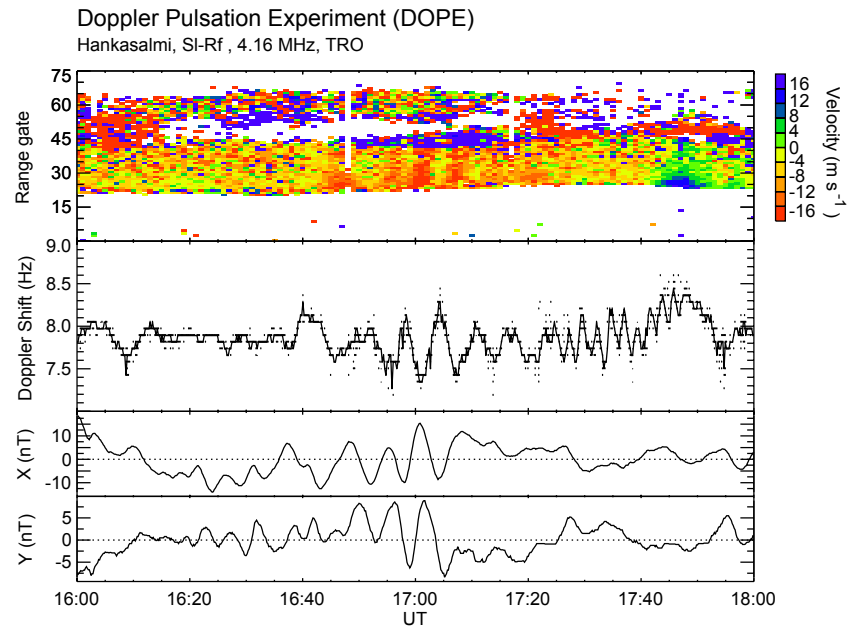

Fig. 1. Top to bottom: SuperDARN Doppler velocity as a function of range and time (Hankasalmi, beam 5); Doppler shift at $4.16 \mathrm{MHz}$ versus time, measured by DOPE; $\mathrm{X}$ and $\mathrm{Y}$ components of the magnetic field perturbations measured at Troms $\varnothing$ for 16:00-18:00 UT, 25 March 2002.

for the DOPE data includes the latter, higher frequency, high- $m$ event at $7 \mathrm{mHz}$. Using the $\mathrm{Y}$ component data from the IMAGE magnetometers, the azimuthal wave number at $2.8 \mathrm{mHz}$, from Eq. (7) was found to be $m \sim 2$. The $m$ number was also estimated using the multiple beam data from the Hankasalmi radar $(m \sim 2)$ and the different propagation paths of DOPE where $m \sim 4$ was obtained. However, the small spatial separation of the beams from DOPE $(0.44 \mathrm{deg})$ make low- $m$ measurements difficult (Yeoman et al., 2000).

The ULF and HF variations shown in Figs. 1 and 2 need to be put into context. The $K_{p}$ index is a general indicator of global magnetic variation activity. For 25 March 2002, the $K_{p}$ activity index was around $2^{+}$, except for the 06:0012:00 UT interval when $K_{p} \sim 0$. ULF wave energy at high latitudes with frequencies less than $10 \mathrm{mHz}$ are often identified as signatures of FLRs. The cross phase spectrum of the data from two latitudinally spaced magnetometers can be used to identify the FLR frequency at the location between the magnetometer sites (e.g. Waters et al., 1991, 1996). An analysis of the Soroya (SOR) and Kilpisjärvi (KIL) magnetometer data is ideal for estimating any resonant frequency detected by the Troms $\varnothing$ magnetometer. Taking various magnetometer pairs from the IMAGE magnetometer network the FLR frequencies versus latitude were obtained from the cross phase data and are shown in Fig. 3. The $2.8 \mathrm{mHz}$ signal seen in the Troms $\varnothing$ magnetometer data is consistent with the FLR continuum for this interval. Therefore, the signal should exhibit features of a shear Alfven wave incident from the magnetosphere onto the ionosphere.

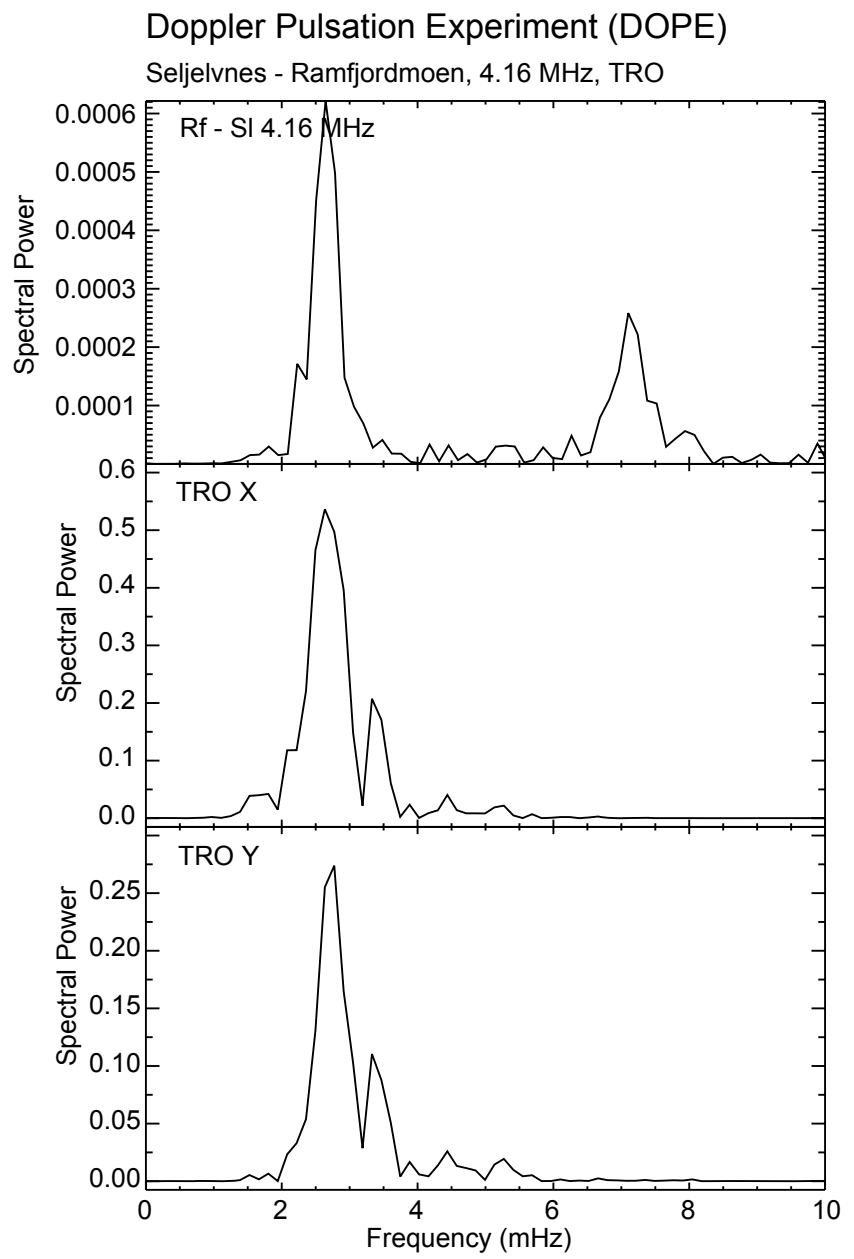

Fig. 2. Power spectrum of the magnetometer and DOPE data shown in Fig. 1.

\subsection{Event 2: 24 March 2001}

This second interval has a more localised spatial structure. The DOPE and Troms $\varnothing$ magnetometer data recorded 04:30 05:30 UT, on 24 March 2001 are shown in Fig. 4. The power spectra of the magnetometer and DOPE time series data are shown in Fig. 5 which identifies a $5 \mathrm{mHz}$ oscillation. At $5 \mathrm{mHz}$, the magnetometer data show equal amplitude for the $\mathrm{X}$ and $\mathrm{Y}$ components at $\sim 3 \mathrm{nT}$. The Doppler shift amplitude is $\sim 0.5 \mathrm{~Hz}$, increasing to $\sim 1 \mathrm{~Hz}$ over 04:55-05:05 UT, then decreasing again. The Hankasalmi SuperDARN data contain a similar oscillation (not shown). A multi-beam analysis of the spatial variation of the phase from the radar data gives an azimuthal wave number of $m \sim 10$. This was close to the estimate obtained using the ground magnetometer data $(m \sim 9)$. An analysis of the phase difference with longitude using the DOPE beams also gave $m \sim 9$. The magnetic activity for this day was moderate to low with $K_{p} \sim 3$. The FLRs as a function of latitude obtained from the IMAGE magnetometer data are shown in Fig. 6 indicating that the $5 \mathrm{mHz}$ signal is part of the 


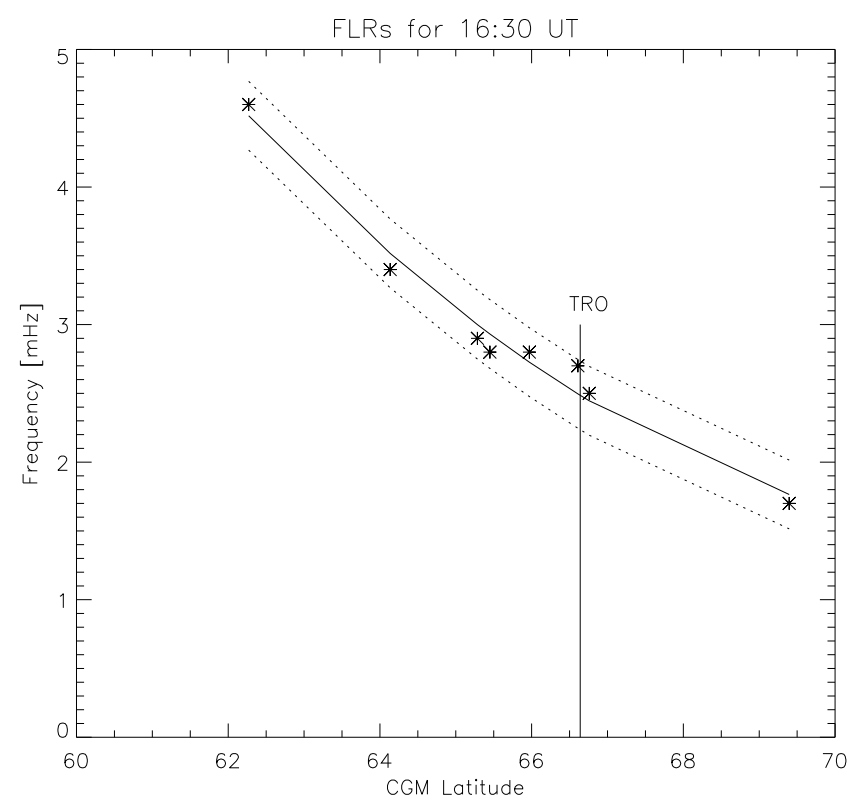

Fig. 3. Latitude variation of the FLR frequencies obtained from IMAGE magnetometer data for 16:00-18:00 UT, 25 March 2002 (see text for details). The latitude of the DOPE instrumentation is marked.

resonance continuum. The higher FLR frequency compared with the first event is most likely due to a decrease in the equatorial plasma mass density near geosynchronous orbit.

These two cases represent low and medium $m$ number ULF wave events. For both of these, the Troms $\varnothing$ dynasonde data were obtained. Modeling the interaction of the ULF with the HF signals requires knowledge of various parameters of the ionosphere as a function of height. The EISCAT dynasonde data were used to calculate the electron concentration with height and these values agreed with those obtained from the IRI2001 model runs. The dynasonde data do not directly provide information on the ion composition with height. However, since the electron concentration values were in good agreement, we have assumed that the ionosphere was reasonably approximated by the IRI2001 model.

\section{Modeling the ULF and HF interaction}

The relationship between the ULF and HF signals in the ionosphere was investigated using the SP model. The ULF electric and magnetic wave fields were computed as a function of altitude as described in Sect. 2. The ULF model requires details of the incident ULF wave modes, horizontal wave numbers and ULF frequency. Using the $m$ number determined from the IMAGE magnetometer data recorded on 25 March 2002, the east-west wave number is $k_{y}=1.1 \times 10^{-6} \mathrm{~m}^{-1}$. Assuming an incident shear Alfvén mode wave at a frequency of $2.8 \mathrm{mHz}$ we now require an es-

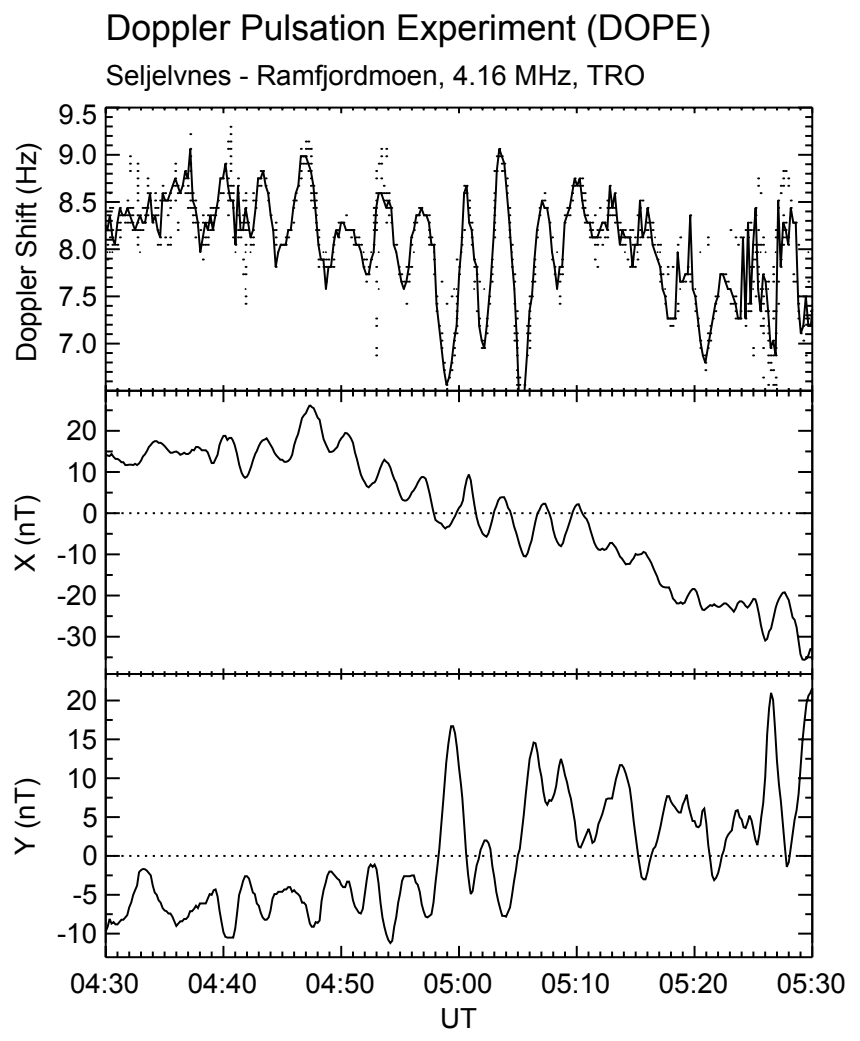

Fig. 4. DOPE and Troms $\emptyset$ magnetometer time series for 04:3005:30 UT, 24 March 2001.

timate for the north-south wave number, $k_{x}$. Since $\nabla \times \mathbf{b}=0$ in the atmosphere, Hughes (1974) pointed out that $k_{y} b_{x} \approx k_{x} b_{y}$. This allows an estimate of the relationship between the wave numbers and the wave magnetic field amplitudes. Given that the ground magnetometer data for the 25 March 2002 show a ratio of $b_{x} / b_{y}=1.5$, we set $k_{x}=1.6 \times 10^{-6} \mathrm{~m}^{-1}$.

Using the solution for the ULF wave fields, the SP model was used to compute the components of the Doppler velocity, $V^{*}$, as defined in Eqs. (4-6). The results are shown in Fig. 7 where we have added a $10 \%$ fast mode mix at $1000 \mathrm{~km}$ (discussed later). The top panel shows the ULF wave magnetic field magnitudes with $b_{x}=6 \mathrm{nT}$ and $b_{y}=4 \mathrm{nT}$ at the ground. The centre panel shows that the magnitude of the $\mathrm{X}$ and $\mathrm{Y}$ components of the electric field of the ULF wave is $\sim 1 \mathrm{mV} / \mathrm{m}$ throughout the ionosphere, decreasing below $80 \mathrm{~km}$ altitude. The shear Alfvén wave reflection coefficient, measured at $1000 \mathrm{~km}$, is -0.98 (Sciffer and Waters, 2002) and the fast mode that is generated by mode conversion mostly in the E-region of the ionosphere, is evanescent, contributing very little as shown by the small values for $V_{1}$. The bottom panel shows the magnitude of the frequency shift in $\mathrm{Hz}$ as a function of the HF signal reflection height. The calculation simulates a vertical incidence ionosonde, incrementing the radio frequency (HF) and finding the reflection height for each frequency. The missing data between $105-140 \mathrm{~km}$ 
Doppler Pulsation Experiment (DOPE)

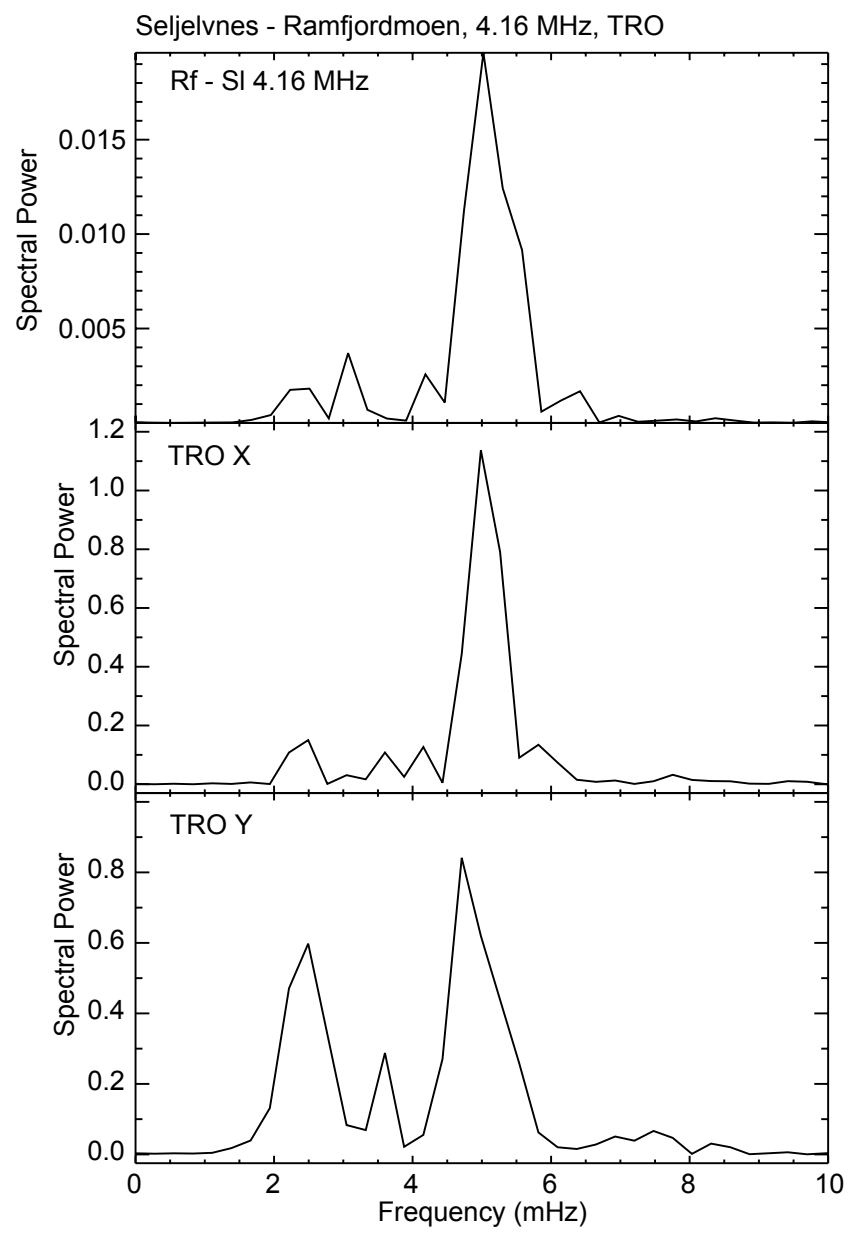

Fig. 5. Power spectrum of the magnetometer and DOPE data shown in Fig. 4.

indicates the valley in the electron density between the $\mathrm{E}$ and $\mathrm{F}$ regions. The DOPE frequency of $4.16 \mathrm{MHz}$ corresponds with an altitude of $200 \mathrm{~km}$. Here the Doppler shifts from the model are $V_{1}=0.002 \mathrm{~Hz}(0.06 \mathrm{~m} / \mathrm{s}), V_{2}=0.34 \mathrm{~Hz}(12 \mathrm{~m} / \mathrm{s})$, $V_{3}=0.01 \mathrm{~Hz}(0.5 \mathrm{~m} / \mathrm{s})$ and $V^{*}=0.34 \mathrm{~Hz}(12 \mathrm{~m} / \mathrm{s})$. Therefore, the major contributor to the Doppler shift is the advection mechanism, $V_{2}=0.34 \mathrm{~Hz}$, driven by the vertical bulk electron motion as a $\mathbf{e} \times \mathbf{B}_{\mathbf{0}}$ drift process. Experimenting with the input fast mode mix at $1000 \mathrm{~km}$ we found that increasing the fast mode component decreased the resulting Doppler shifts. This is due to the horizontal ULF wave electric field vector swinging around into the $\mathrm{X}$ direction (aligning with the transverse component of $\mathbf{B}_{\mathbf{0}}$ ) as more fast mode energy is added, reducing the magnitude of $\mathbf{e} \times \mathbf{B}_{\mathbf{0}}$.

The ULF and SP models were also used to compare the ground magnetometer and DOPE data recorded on 24 March 2001. Since the $\mathrm{X}$ and $\mathrm{Y}$ component magnetometer data have equal amplitude, and given an azimuthal wavenumber, $m \sim 9$, then $k_{x}=k_{y}=4.6 \times 10^{-6}$. The results of modeling the

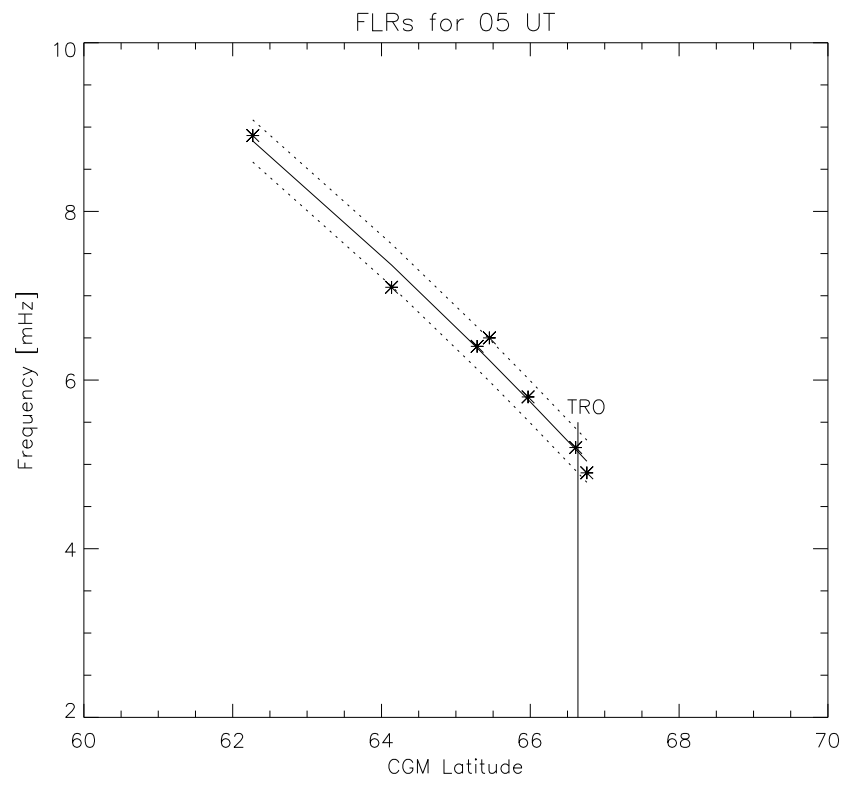

Fig. 6. Latitude variation of the FLR frequencies obtained from IMAGE magnetometer data for 04:30-05:30 UT, 24 March 2001. The latitude of the DOPE instrumentation is marked.

ULF and Doppler variations are shown in Fig. 8. An incident shear Alfvén wave mode was used. For this case, when some fast mode was mixed at the top boundary of the model $(1000 \mathrm{~km})$, the Doppler shift increased. The top panel shows the well known $90^{\circ}$ rotation of the wave fields as they pass from the ionosphere where $\nabla \times \mathbf{b} \neq \mathbf{0}$ into the neutral atmosphere where $\nabla \times \mathbf{b}=0$ (Hughes, 1983). The ULF wave horizontal electric fields are essentially constant with height at $\sim 2 \mathrm{mV} / \mathrm{m}$. For the DOPE operating frequency at $4.16 \mathrm{MHz}$, the reflection altitude was $226 \mathrm{~km}$. At this altitude the Doppler shifts from the model were $V_{1}=0.002 \mathrm{~Hz}$ $(0.07 \mathrm{~m} / \mathrm{s}), V_{2}=0.65 \mathrm{~Hz}(23 \mathrm{~m} / \mathrm{s}), V_{3}=0.09 \mathrm{~Hz}(3.3 \mathrm{~m} / \mathrm{s})$ and $V^{*}=0.62 \mathrm{~Hz}(22 \mathrm{~m} / \mathrm{s})$. Therefore, the major contributor is once again the advection mechanism with the Doppler shift driven by the vertical bulk electron motion.

\section{Discussion}

The time variation of Doppler shifts obtained from DOPE compared with the magnetometer data and associated modeling for both events show very good agreement. The experimental data constrains the model parameters to a certain extent. These are the Doppler shifts measured by the HF instrumentation, the magnitudes of the horizontal components of the ULF magnetic perturbations from ground magnetometers and the ULF and HF frequencies. The less certain parameters in the modeling process are the horizontal spatial structure of the ULF energy and the ULF wave mode mix. 

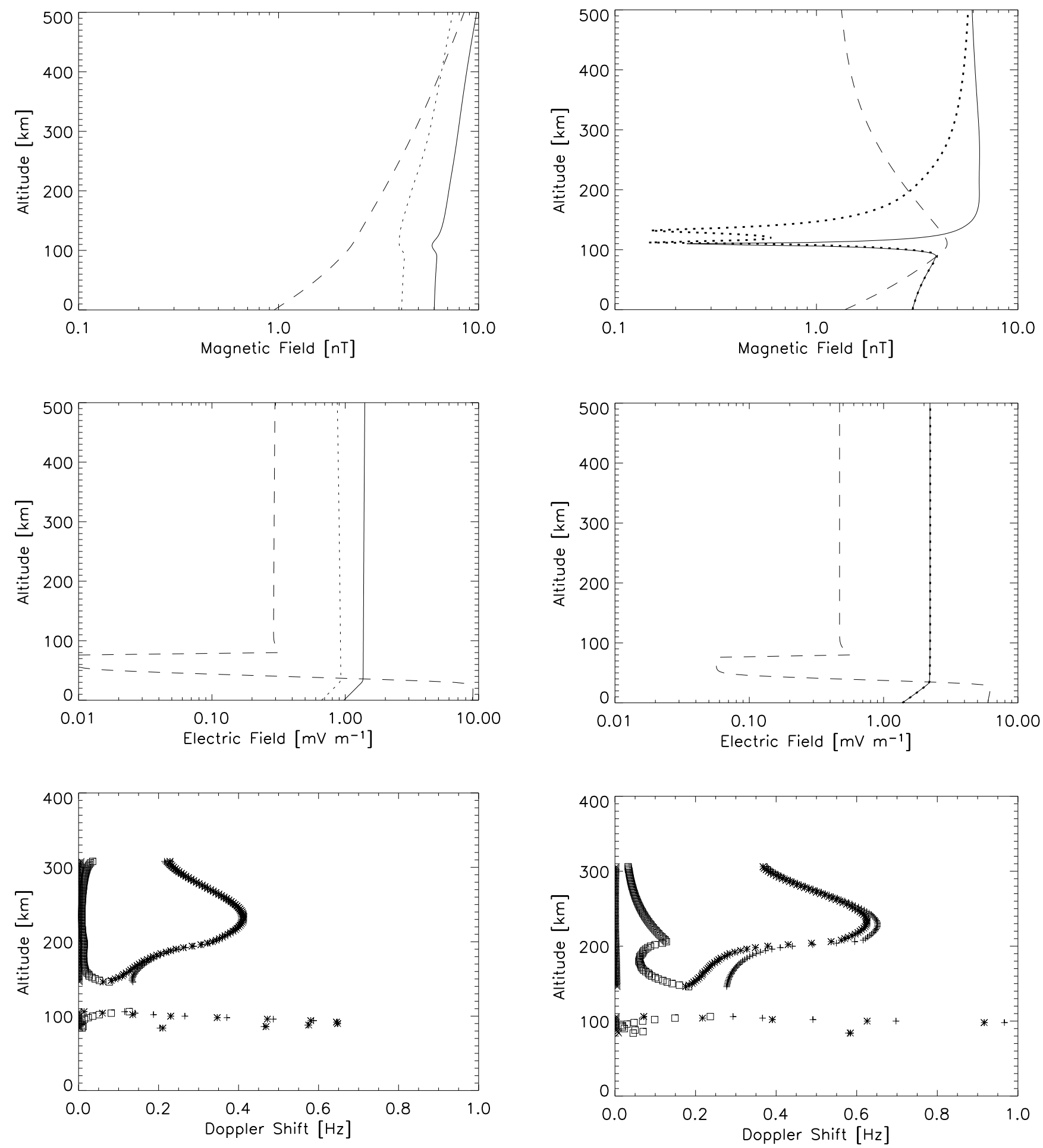

Fig. 7. Model results of the ULF electric and magnetic fields and the associated Doppler shift with altitude. The parameters associated with 16:00-18:00 UT, 25 March 2002 were used. (a) ULF wave magnetic field magnitudes where $b_{x}$ (solid), $b_{y}$ (dotted), $b_{z}$ (dashed). (b) ULF wave electric field magnitudes where $e_{x}$ (solid), $e_{y}$ (dotted), $e_{z}$ (dashed). (c) Doppler shifts where $V_{1}(\mathrm{X}), V_{2}(+)$, $V_{3}$ (squares) and $V^{*}(*)$.

Fig. 8. Model results of the ULF electric and magnetic fields and the associated Doppler shift with altitude. The parameters associated with 04:30-05:30 UT, 24 March 2001 were used. (a) ULF wave magnetic field magnitudes where $b_{x}$ (solid), $b_{y}$ (dotted), $b_{z}$ (dashed). (b) ULF wave electric field magnitudes where $e_{x}$ (solid), $e_{y}$ (dotted), $e_{z}$ (dashed). (c) Doppler shifts where $V_{1}(\mathrm{X}), V_{2}(+)$, $V_{3}$ (squares) and $V^{*}(*)$. 
The 1-D modeling used for the ULF wave information assumes horizontal spatial structure according to $e^{i\left(k_{x} x+k_{y} y-\omega t\right)}$. The parameter, $k_{y}$, or $m$ number is routinely used in ULF wave research. Given that the longitudinal spacing for the propagation paths used by DOPE is $\sim 0.4$ degree, only the high- $m$ events yield low uncertainty estimates for $k_{y}$. Estimating $m$ numbers from ground magnetometer data can give inaccurate values due to spatial integration effects (Ponomarenko et al., 2001). Ideally, the SuperDARN instrumentation, using ionosphere scatter signals from the crossed beam pattern from at least two radars would provide unprecedented spatial structure information of the ULF perturbations. However, despite a search for such cases, no crossed beam, ionospheric scatter ULF wave events have been identified.

For both events presented here, the ULF perturbations were found in the Hankasalmi radar data. The associated radar forming crossed beams is located in Iceland and showed no returns. This turned out to be irrelevant as the ULF perturbations seen in the Hankasalmi radar data were from ground scatter and thus correspond to half the range normally shown on SuperDARN data plots. Fortunately, this placed the Hankasalmi radar beam ionosphere 'reflection' scatter very close to the Troms $\emptyset$ magnetometer. The spatial structure of the Doppler velocity amplitude and phase for the $2.8 \mathrm{mHz}$ ULF wave recorded on 25 March 2002 are shown in Fig. 9. The variation of the phase with longitude provides the estimate for $k_{y}$ while the Doppler velocity magnitudes agree with those from DOPE. The finding that the $m$ value estimates obtained from the magnetometer, DOPE and the SuperDARN data are consistent indicates that we have realistic estimates for $k_{y}$.

An estimate for $k_{x}$ is not so straightforward. An estimate from Fig. 9 may appear possible, provided scatter from sufficient ranges are obtained. A complication involves the latitudinal spatial structure associated with an FLR. The quality of the resonance alters the amplitude and phasing with latitude that defies a simple $k_{x}$ description. For modeling in 1-D, we have used the relationship derived from $\nabla \times \mathbf{b}=0$ to obtain $k_{x}$ from $k_{y}, b_{x}$, and $b_{y}$. This approach appears to be adequate for modeling the correct ratio of the ground magnetic field perturbations and the Doppler shifts.

In order to determine how the Doppler shift is related to the choice of $k_{x}$ we have run the modeling for two cases where $k_{x}$ was varied. The parameters for 24 March 2001 were used where the ULF wave contained a $10 \%$ fast mode mix at the top boundary $(1000 \mathrm{~km})$, at a frequency of $5 \mathrm{mHz}$, and the ionosphere and atmosphere models were set for the Troms $\varnothing$ location and 05:00 UT. The first case assumes that the ground magnetometers record equal amplitude for the $b_{x}$ and $b_{y}$ perturbations. Therefore, we varied $k_{x}$ keeping $k_{x}=k_{y}$. The amplitude of the Doppler shift $\left(V^{*}\right.$ in $\mathrm{Hz}$ ) as a function of altitude and $k_{x}$ is shown in the top panel of Fig. 10. The amplitude of the magnetic perturbations at the ground have been kept at $5 \mathrm{nT}$ for all runs. The Doppler shift scales linearly
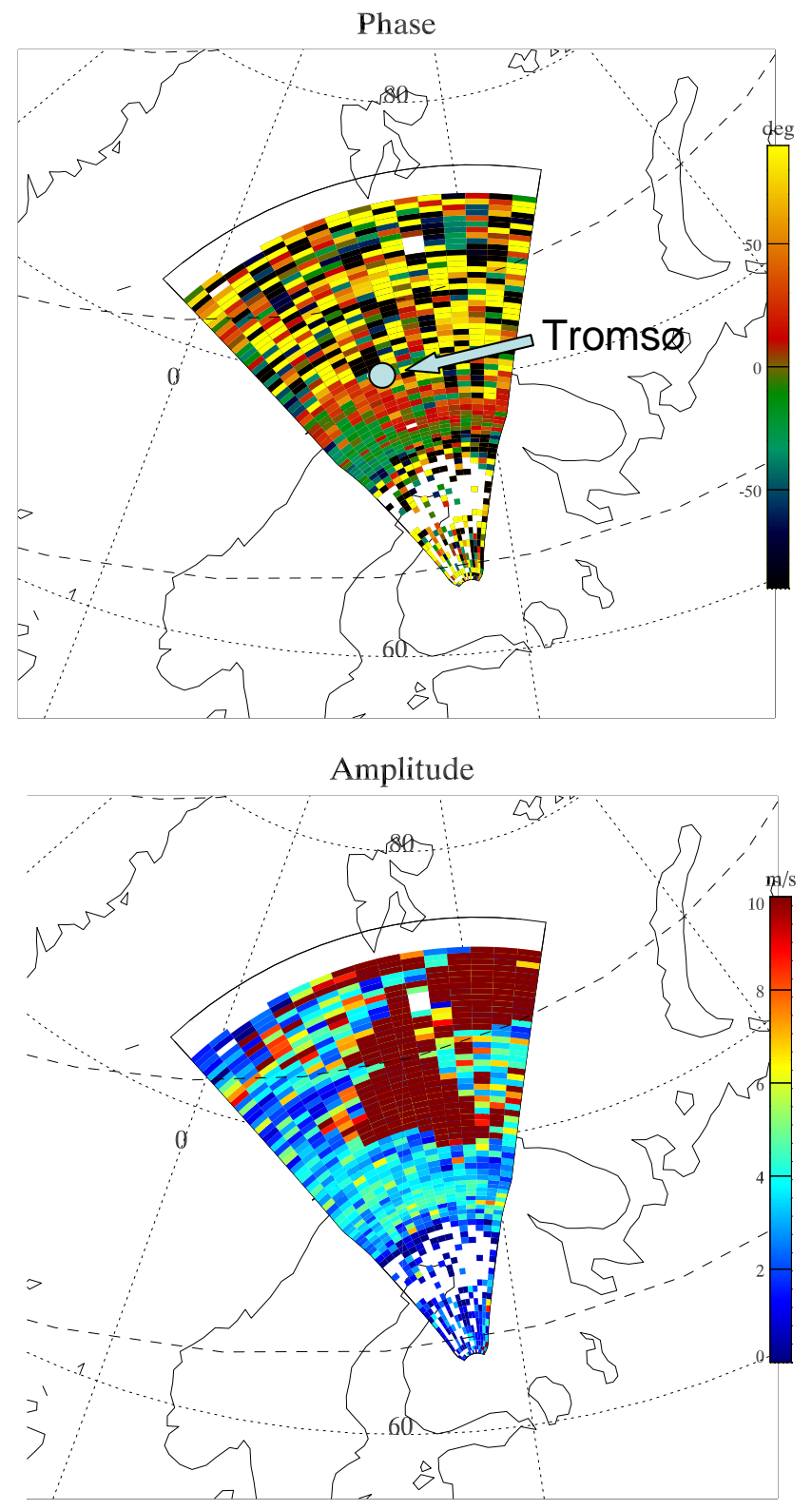

Fig. 9. Hankasalmi SuperDARN radar data for 16:30-17:30 UT, 25 March 2002. Spatial variation of the amplitude and phase of the Doppler velocity variations at $2.8 \mathrm{mHz}$.

with magnetic perturbation amplitude. The bottom panel in Fig. 10 shows the dependence of the Doppler shift (in $\mathrm{Hz}$ ) with $k_{x}$, keeping $k_{y}=1.5 \times 10^{-6} \mathrm{~m}^{-1}$, an $m$ number of 3.3 .

The major contribution to the Doppler shift comes from the advection mechanism, $\mathbf{e} \times \mathbf{B}_{\mathbf{0}, \mathbf{x}}$. Therefore, the Doppler shift values in Fig. 10 reflect the orientation and magnitude of the horizontal ULF electric field. The variation of the ULF electric field depends on the details of the interaction of ULF energy with the ionosphere including complex reflection and ULF wave mode conversion coefficients (Sciffer and Waters, 

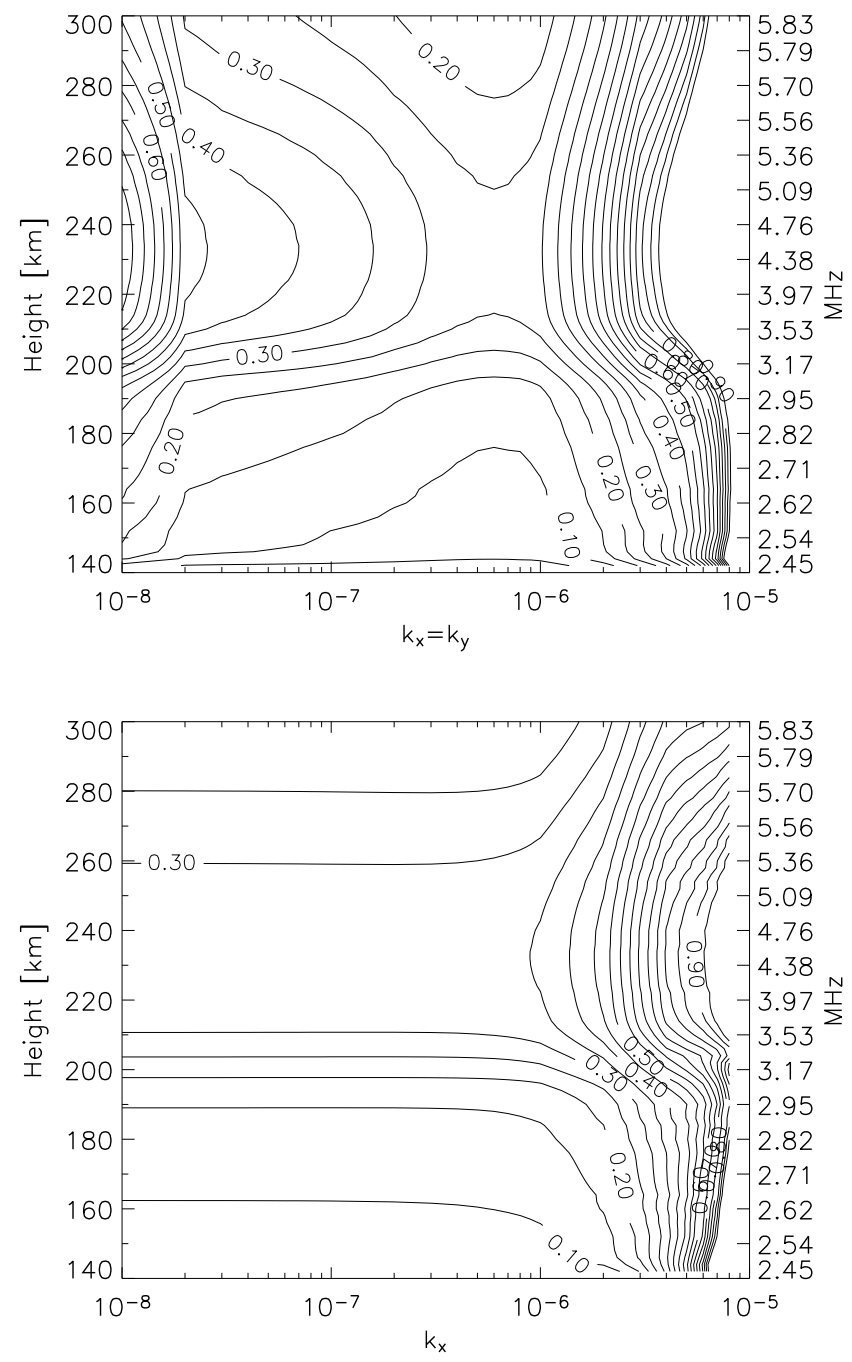

Fig. 10. The Doppler shift $\left(V^{*}\right.$ in $\mathrm{Hz}$ ) for a $5 \mathrm{mHz}$ ULF wave with $10 \%$ fast mode mix (at $1000 \mathrm{~km}$ altitude) as a function of altitude. The right hand side axis shows the HF "reflection" frequencies for the ionosphere above Troms $\varnothing$ for 05:00 UT, 24 March 2001. Top: Variation for $k_{x}=k_{y}$ and Bottom: for $k_{y}=1.5 \times 10^{-6} \mathrm{~m}^{-1}$.

2002), the distance for evanescant components to decrease in amplitude and how these mix with the incident ULF energy (Sciffer et al., 2005).

For Fig. 10 where $k_{x}=k_{y}, e_{x}=e_{y}$ and the orientation of the electric field is $45^{\circ}$ from the north-south direction. For $k_{x}>1 \times 10^{-6} \mathrm{~m}^{-1}$, the fast mode is evanescant and the amplitude decreases with altitude. The smaller wave field resulting from the decreasing fast mode is boosted in the scaling process to keep $b_{y}=5 \mathrm{nT}$ at the ground, giving the larger Doppler shifts. For $k_{x}<3 \times 10^{-7} \mathrm{~m}^{-1}$ the fast mode has only real $k_{z}$. The increased Doppler shifts for these smaller values for $k_{x}$ arise from the increased electric field magnitudes resulting from the complex addition of the incident and reflected fast and shear Alfvén modes.
For the bottom panel in Fig. 10, $k_{y}$ and $b_{y}$ at the ground are kept constant while $k_{x}$ varies. As $k_{x}$ increases, the orientation and magnitude of the horizontal component of the ULF wave electric field changes. In particular, while $e_{y}$ stays relatively constant, $e_{x}$ begins smaller than $e_{y}$, becomes equal for $k_{x}=1.5 \times 10^{-6} \mathrm{~m}^{-1}$ and ends up larger than $e_{y}$. Therefore, the larger $e_{y}$ determines the Doppler shift giving the quite constant values up until $k_{x} \sim 1 \times 10^{-6} \mathrm{~m}^{-1}$. Above that, the evanescent fields increase by scaling to keep $b_{y}$ at the ground at $5 \mathrm{nT}$.

The exploration of associated Doppler shifts for more realistic spatial structures associated with FLRs can be achieved in higher dimesional ULF wave models. Extending the ULF wave modeling into at least a 2-D magnetosphere that includes a realistic ionosphere description is work in progress. This will also allow for non-uniformity of the ionosphere and more complex ULF wave spatial structure in the horizontal plane.

Estimating the MHD wave mode mixture is difficult and most ULF wave models for the ionosphere have only considered incident shear Alfvén mode energy. In general, a ULF disturbance in the magnetosphere may contain shear Alfvén mode from the FLR continuum and fast mode energy arising from mode conversion by the anisotropic ionosphere and the input ULF energy source. An indication of whether there is some shear Alfvén mode can be obtained by the proximity of the observed ULF frequency to the FLR frequency. This is the purpose of Figs. 3 and 6 which indicate that both events are likely to have a significant shear Alfvén component. Furthermore, $k_{x}$ and $k_{y}$ along with the local Alfvén speed determine whether the fast mode will propagate in the vertical direction or is evanescent. The extension of the ULF modeling in higher dimensions will allow a more complete understanding of the appropriate ULF wave mode mix.

\section{Conclusion}

We have described the first comparisons of observed changes in radio frequency with the predictions of the SP model that use parameters relevant for particular ULF wave events. The experimental constraints are the radio frequency, the observed Doppler shifts and the ULF magnetic perturbations at the ground. Using models for the atmosphere and ionosphere composition, we have shown that the SP model predicts the correct magnitudes for the Doppler shifts and identifies the advection mechanism as the dominant process that changes the HF frequency, caused by the presence of ULF waves interacting with the ionosphere. At present the SP model is applicable for vertical incidence of the HF signal. Future improvements will allow for oblique HF propagation and higher dimensional ULF wave modeling that more completely describes the transfer of ULF wave energy between the magnetosphere and ionosphere. 
Acknowledgements. This work was supported by the University of Newcastle. We thank the institutes who maintain the IMAGE magnetometer array.

Topical Editor M. Pinnock thanks two referees for their help in evaluating this paper.

\section{References}

Allan, W., Poulter, E. M., and Nielson, E.: Pc5 pulsations associated with ring current proton drifts: STARE radar observations, Planet. Space Sci., 31, 1279-1289, 1983.

Bennett, J. A.: The calculation of Doppler shifts due to changing ionosphere, J. Atmos. Terr. Phys., 29, 887-891, 1967.

Budden, K.: The Propagation of Radio Waves, Cambridge University Press, Cambridge, United Kingdom, 1985.

Chen, L. and Hasegawa, A.: A theory of long period magnetic pulsations 1 . Steady state excitation of field line resonances, J. Geophys. Res., 79, 1024-1032, 1974.

Dungey, J. W.: Electrodynamics of the Outer Atmosphere, Pennsylvania State Uni., Ionos. Res. Lab. Sci. Rep., 69, 1954.

Ellis, P. and Southwood., D. J.: Reflection of Alfvén waves by nonuniform ionospheres, Planet. Space Sci., 31, 107-117, 1983.

Fenrich, F. R., Samson, J. C., Sofko, G., and Greenwald, R. A.: ULF high- and low-m field line resonances observed with the Super Dual Auroral Radar Network, J. Geophys. Res., 100, 21 535$21547,1995$.

Hedin, A. E.: Extension of the MSIS thermosphere model into the middle and lower atmosphere, J. Geophys. Res., 96, 1159-1172, 1991.

Herron, T. J.: Phase characteristics of geomagnetic micropulsations, J. Geophys. Res., 71, 871-889, 1966.

Hughes, W. J.: The effect of the atmosphere and ionosphere on long period magnetospheric micropulsations, Planet. Space Sci., 22, 1157-1172, 1974.

Hughes, W. J.: Hydromagnetic waves in the magnetosphere, in: Solar-Terrestrial Physics, edited by: Carovillano, R. L. and Forbes, J. M., D. Reidel Pub. Co., 1983.

Hughes, W. J. and Southwood, D.: The screening of micropulsation signals by the atmosphere and ionosphere, J. Geophys. Res., 81, 3234-3240, 1976a.

Hughes, W. J. and Southwood, D.: An illustration of modification of geomagnetic pulsation structure by the ionosphere, J. Geophys. Res., 81, 3241-3247, 1976b.

Jacobs, J. A. and Watanabe, T.: Doppler frequency changes in radio waves propagating through a moving ionosphere, Radio Sci., 1, 257-264, 1966.

Luhr, H.: The IMAGE magnetometer network, STEP Int. Newslett., 4, 4, 1994

Menk, F. W.: Characterization of ionospheric Doppler oscillations in the Pc3-4 and Pi2 magnetic pulsation frequency range, Planet Space Sci., 40, 459-507, 1992.

Nishida, A.: Ionospheric screening effect and storm sudden commencement, J. Geophys. Res., 69, 1861-1874, 1964.

Olson, J. V. and Rostoker, G.: Longitudional phase variation of Pc 4-5 micropulsations., J. Geophys. Res., 83, 2481-2488, 1978.

Pitteway, M. L. V.: The numerical calculation of wave fields, reflection coefficients and polarizations for long radio waves in the lower ionosphere., Royal Soc. Phil. Trans., 257, 219-239, 1965.
Ponomarenko, P. V., Waters, C. L., Sciffer, M. D., and Fraser, B. J.: Spatial structure of ULF waves: Comparison of magnetometer and Super Dual Auroral Radar Network data, J. Geophys. Res., 106, 10 509-10 517, 2001.

Poole, A. W. V. and Sutcliffe, P. R.: Mechanisms for observed total electron content pulsations at mid latitudes, J. Atmos. Terr. Phys., 49, 231-236, 1987.

Poole, A. W. V., Sutcliffe, P. R., and Walker, A. D. M.: The relationship between ULF geomagnetic pulsations and ionospheric doppler oscillations: Derivation of a model., J. Geophys. Res., 93, 14 656-14 664, 1988.

Rishbeth, H. and Garriott, O. K.: Relationship between simultaneous geomagnetic and ionospheric oscillations, Radio Sci., 68D, 339-343, 1964.

Ruohoniemi, J. M., Greenwald, R. A., and Baker, K. B.: HF radar observations of Pc5 field line resonances in the mignight/early morning MLT sector, J. Geophys. Res., 96, 15 697, 1991.

Samson, J. C. and Rostoker, G.: Latitude-dependent characteristics of high latitude Pc4 and Pc5 micropulsations, J. Geophys. Res., 77, 6133-6144, 1972.

Sciffer, M. D. and Waters, C. L.: Propagation of ULF waves through the ionosphere: Analytic solutions for oblique magnetic fields, J. Geophys. Res., 107, 1297-1311, 2002

Sciffer, M. D., Waters, C. L., and Menk, F. W.: Propagation of ULF waves through the ionosphere: Inductive effect for oblique magnetic fields, Ann. Geophys., 22, 1155-1169, 2004, http://www.ann-geophys.net/22/1155/2004/.

Sciffer, M. D., Waters, C. L., and Menk, F. W.: A numerical model to investigate the polarisation azimuth of ULF waves through the ionosphere with oblique magnetic fields, Ann. Geophys., 23, 3457-3471, 2005, http://www.ann-geophys.net/23/3457/2005/.

Southwood, D. J.: The hydromagnmetic stability of the magnetospheric boundary, Planet. Space Sci., 16, 587-605, 1968.

Southwood, D. J.: Some features of field line resonances in the magnetosphere, Planet. Space Sci., 22, 483-491, 1974.

Stix, T. H.: The theory of plasma waves., McGraw-Hill, New York., 1962.

Sutcliffe, P. R. and Poole, A. W. V.: Ionospheric Doppler and electron velocities in the presence of ULF waves, J. Geophys. Res., 94, 13 505-13 514, 1989.

Sutcliffe, P. R. and Poole, A. W. V.: The relatuionship between ULF geomagnetic pulsations and ionospheric Doppler oscillations: Model predictions, Planet. Space Sci., 38, 1581-1589, 1990.

Takahashi, K.: ULF waves in the magnetosphere, Rev. Geophys. Suppl., p. 1066, 1991.

Walker, A. D. M., Greenwald, R. A., Stuart, W. F., and Green, C. A.: STARE auroral radar observations of Pc 5 geomagnetic pulsations, J. Geophys. Res., 84, 3371-3388, 1979.

Watermann, J.: Observations of correlated ULF fluctuations in the geomagnetic field and in the phase path of ionospheric HF soundings, J. Geophys., 61, 39-45, 1987.

Waters, C. L.: ULF resonance structure in the magnetosphere, Adv. Space Res., 25, 1541-1558, 2000.

Waters, C. L., Menk, F. W., and Fraser, B. J.: The resonant structure of low latitude Pc 3 geomagnetic pulsations, Geophys. Res. Lett., 18, 2293-2296, 1991.

Waters, C. L., Samson, J. C., and Donovan, E. F.: Variation of plas- 
matrough density derived from magnetospheric field line resonances, J. Geophys. Res., 101, 24 737-24 745, 1996.

Waters, C. L., Sciffer, M. D., Fraser, B. J., Brand, K., Foulkes, K., Menk, F. W., Saka, O., and Yumoto, K.: The phase structure of very low latitude ULF waves across dawn, J. Geophys. Res., 106, 15 599-15 607, 2001.

Wright, D. M., Yeoman, T. K., and Chapman, P. J.: High latitude HF Doppler oscillations of ULF waves: 1 . Waves with large spatial scale sizes, Ann. Geophys., 15, 1548-1556, 1997, http://www.ann-geophys.net/15/1548/1997/.

Wright, D. M., Yeoman, T. K., and Jones, T. B.: ULF wave occurrence statistics in a high-latitude HF Doppler sounder, Ann. Geophys., 17, 749-758, 1999, http://www.ann-geophys.net/17/749/1999/.

Yeoman, T. K., Lester, M., Orr, D., and Luhr, H.: Ionospheric boundary conditions of hydromagnetic waves: the dependence on azimuthal wave number and a case study, Planet. Space Sci., 38, 1315-1325, 1990.
Yeoman, T. K., Wright, D. M., Chapman, P. J., and Stockton-Chalk, A. B.: High latitude observations of ULF waves with large azimuthal wavenumbers, J. Geophys. Res., 105, 5453-5462, 2000.

Yumoto, K., Saito, T., Akasofu, S. I., Tsurutani, B. T., and Smith, E. J.: Propagation mechanism of daytime Pc3-4 pulsations observed at synchronous orbit and multiple ground-based stations, J. Geophys. Res., 90, 6439-6450, 1985.

Zhang, D. Y. and Cole, K. D.: Some aspects of ULF electromagnetic wave relations in a stratified ionosphere by the method of boundary value problem, J. Atmos. Terr. Phys., 56, 681-690, 1994.

Zhang, D. Y. and Cole, K. D.: Formulation and computation of hydromagnetic wave penetration into the equatorial ionosphere and atmosphere, J. Atmos. Terr. Phys., 57, 813-819, 1995.

Ziesolleck, C. W. S., Fenrich, F. R., Samson, J. C., and McDiarmid, D. R.: Pc5 field line resonance frequencies and structure observed by SuperDARN and CANOPUS, J. Geophys. Res., 103, 11771-11 785, 1998. 